\title{
Radiología en la Pandemia COVID-19: Uso actual, recomendaciones para la estructuración del informe radiológico y experiencia de nuestro departamento
}

\author{
Felipe Castillo A. ${ }^{*}$, Diego Bazaes N. ${ }^{2}$, Álvaro Huete G. $^{3}$
}

1. Radiólogo, Unidad de Imágenes tóraco-abdominales, Red de Salud UC-Christus. Santiago, Chile.

2. Interno de Medicina, Pontificia Universidad Católica de Chile. Santiago, Chile.

3. Radiólogo, Profesor Asociado, Departamento de Radiología, Pontificia Universidad Católica de Chile. Santiago, Chile.

Radiology in the COVID-19 Pandemic: Current role, recommendations for structured reporting and experience of our Department

\section{Resumen:}

La pandemia causada por el nuevo coronavirus (SARS-CoV-2) ha derivado en nuevos desafíos en la manera que radiología apoya el trabajo clínico y presta servicios oportunos. El presente artículo revisa las principales publicaciones en la literatura radiológica a la fecha, con énfasis en los sistemas de informe estructurado en tomografía computada y radiografía de tórax. Se relata además nuestra experiencia en las modificaciones realizadas en el Departamento de Radiología para hacer frente a la pandemia.

Palabras clave: Coronavirus; COVID-19; Radiografía; Tomografía computada.

\begin{abstract}
:
The pandemic caused by the new coronavirus (SARS-CoV-2) has imposed new challenges to the way radiology supports referring clinicians and provides timely services. This article reviews the main radiological publications on COVID-19 to date, with an emphasis on structured reporting schemes in computed tomography and chest radiography. The modifications to clinical practice and academic activities made in our Radiology Department to face the pandemic are also provided.
\end{abstract}

Keywords: Computed tomography; Coronavirus; COVID-19; Radiography.

Castillo F. et al. Radiología en la Pandemia COVID-19: Uso actual, recomendaciones para la estructuración del informe radiológico y experiencia de nuestro departamento. Rev Chil Radiol 2020; 26(3): 88-99.

*Correo electrónico: Felipe Castillo A./ fncastil@uc.cl

Trabajo enviado el 24 de mayo de 2020. Aceptado para publicación el 03 de julio de 2020.

\section{Introducción}

La infección por nuevo coronavirus SARS-CoV-2, declarada pandemia por la Organización Mundial de la Salud el 11 de marzo del 2020', ha causado un alto número de contagios y decesos desde su brote inicial en Wuhan, China. La enfermedad resultante de la infección, denominada COVID-19, se caracteriza por una insuficiencia respiratoria potencialmente mortal.

La emergencia de esta nueva pandemia obliga a definir el rol que ejerce la imagenología en el manejo de pacientes con sospecha o confirmación de COVID-19. En el contexto del diagnóstico inicial es importante además considerar las limitaciones reportadas del test de laboratorio utilizado para confirmar la enfermedad - reacción en cadena de polimerasa con transcriptasa reversa (RT-PCR): cuenta con una sensibilidad diagnóstica moderada, demora de hasta 4 días en convertir a un resultado positivo y existe una latencia variable en la entrega del resultado.

El objetivo de este artículo es revisar los principales tópicos publicados en la literatura radiológica en COVID-19 existentes a la fecha de redacción del manuscrito (14 de junio), con énfasis en las normas de informe estructurado en radiografía de tórax y tomografía computada de tórax. Además, se comparte la experiencia local de nuestro Departamento de Radiología durante el desarrollo de la pandemia. 


\section{Indicaciones de imagen}

Al inicio de la pandemia, las principales sociedades radiológicas, entre ellas el Colegio Americano de Radiología (ACR), demostraron su preocupación por el aumento de estudios de imágenes realizados en pacientes con sospecha o confirmación de COVID-19, advirtiendo en sus comunicados ${ }^{2}$ que tanto la radiografía de tórax (RxT) como tomografía computada de tórax (TC) no son exámenes recomendados como métodos de screening ni confirmación de la enfermedad. Lo anterior con un énfasis en evitar la exposición innecesaria del personal de salud durante la obtención de estos estudios.

Este enfoque, sin embargo, ha sido posteriormente reinterpretado por la Sociedad Fleischner, que a través de un consenso publicado con fecha 7 de abril $^{3}$ argumenta que, dado que existen significativas diferencias en la cantidad de recursos y prevalencia de enfermedad entre los distintos sistemas de salud del mundo, se genera un rol potencial para el uso de RxT y TC en los algoritmos de manejo, en particular en tres escenarios clínicos posibles, que consideran además la severidad de los síntomas clínicos.

El primer escenario consiste en un paciente que se presenta con síntomas respiratorios leves, con cualquier probabilidad pre-test de infección y en un ambiente sin limitaciones de recursos. El segundo escenario contempla un paciente con síntomas respiratorios moderados a severos, independiente de la probabilidad pre-test de infección por COVID-19 y sin limitaciones de recursos críticos. El último escenario planteado consiste en un paciente con las mismas características que el segundo, pero en un ambiente con alta carga de enfermedad comunitaria y con limitaciones críticas de recursos.

La Sociedad Fleischner recomienda en este contexto el uso de RxT y/o TC en: 1) casos confirmados con COVID-19 que sufren descompensación clínica y 2) pacientes con síntomas respiratorios moderados o severos en los que se sospecha la enfermedad, en un sistema con recursos limitados y una alta probabilidad pre-test de COVID-19 (tercer escenario). Por otro lado, desaconsejan su uso en pacientes que se presentan con síntomas respiratorios leves, a excepción de quienes estén en riesgo de progresión de enfermedad.

\section{Tomografía computada}

El rendimiento de la TC en COVID-19 ha sido reportado en diferentes series, con un reciente meta-análisis demostrando valores de sensibilidad y especificidad de $94 \%$ y $37 \%$ respectivamente 4 . Los valores predictivos positivo y negativo para la infección en un segundo estudio fueron de $92 \%$ y $42 \% 5$, asumiendo una probabilidad pre-test en la población de un $85 \%$. Estos valores de rendimiento diagnóstico le dan peso a la TC como un método de estudio válido en pacientes con sospecha o confirmación de enfermedad, siendo sus indicaciones aún motivo de debate a medida que nueva evidencia científica se publica (Ver Indicaciones de imagen).

\section{Hallazgos tomográficos Frecuentes}

Los hallazgos tomográficos reportados con mayor frecuencia en las series publicadas ${ }^{6}$ de pacientes con enfermedad confirmada con COVID-19, corresponden a opacidades pulmonares con densidad en vidrio esmerilado (OVE) (53\%-100\%), OVE asociadas a focos de condensación (27\%-72\%) y engrosamiento intersticial con patrón de tipo empedrado (crazy-paving) (19\%) (Figura 1). La morfología de las opacidades suele ser redondeada o rectangular, y la distribución zonal en el parénquima pulmonar ocurre predominantemente de forma bilateral y periférica (93\%) y hacia las zonas posteriores e inferiores (93\%).

\section{Infrecuentes}

Otros signos menos frecuentemente reportados corresponden al signo del halo inverso (10\%), broncograma aéreo, bandas lineales parenquimatosas y engrosamiento parietal vascular, siendo aún menos frecuentes la presencia de derrame pleural (4-7\%) y adenopatías mediastínicas $(2 \%)^{6}$ (Figura 2).

\section{Evolución temporal}

Existe una relación entre la frecuencia de las alteraciones tomográficas y el momento de adquisición del examen en el curso de la enfermedad ${ }^{7}$. Previo al inicio de síntomas, hasta un $60 \%$ de las TC pueden no mostrar alteraciones, un $20 \%$ demostrar OVE y el $20 \%$ restante focos de condensación. Hay además un período estimado de hasta 2 a 6 días desde el inicio de los síntomas en donde pueden no observarse alteraciones.

En estadíos tempranos ( 0 - 5 días), el patrón predominante son las OVE (62\%), seguidas por focos de condensación (23\%), y a medida que progresan los días de enfermedad, la prevalencia de OVE disminuye $(45 \%)$ a expensas de un aumento en el porcentaje de un patrón mixto determinado por OVE y focos de condensación (38\%), este último haciéndose el patrón más prevalente desde los 12 días de enfermedad. El compromiso unilateral es raro y solo visualizado en el inicio y estadíos muy tardíos de la enfermedad?.

\section{Informe estructurado en TC RSNA / STR / ACR}

Con fecha 25 de marzo, la Sociedad de Radiología de Norteamérica (RSNA), en conjunto con la Sociedad de Radiología Torácica (STR) y Colegio Americano de Radiología (ACR), publica un consenso para guiar el uso de informes estructurados en reportar la probabilidad de infección por COVID-19 en TC ${ }^{8}$. Este 
consenso establece 4 categorías y ha tenido amplia difusión en la comunidad radiológica, incluyendo la Sociedad Chilena de Radiología, que recientemente a través de su capítulo de Tórax propuso en su base un modelo de informe estructurado ${ }^{\text {. }}$

Las 4 categorías del consenso RSNA y la terminología sugerida por nuestro grupo (Tabla 1) corresponden a:
A) Patrón típico: Hallazgos que han sido con mayor frecuencia y especificidad reportados en neumonías por COVID-19 (Ver hallazgos tomográficos frecuentes), siendo los principales diagnósticos diferenciales neumonías virales por agentes no COVID-19 (p. ej: influenza) y patrones de injuria pulmonar aguda (p. ej: neumonía organizante) (Figuras 3A-B).
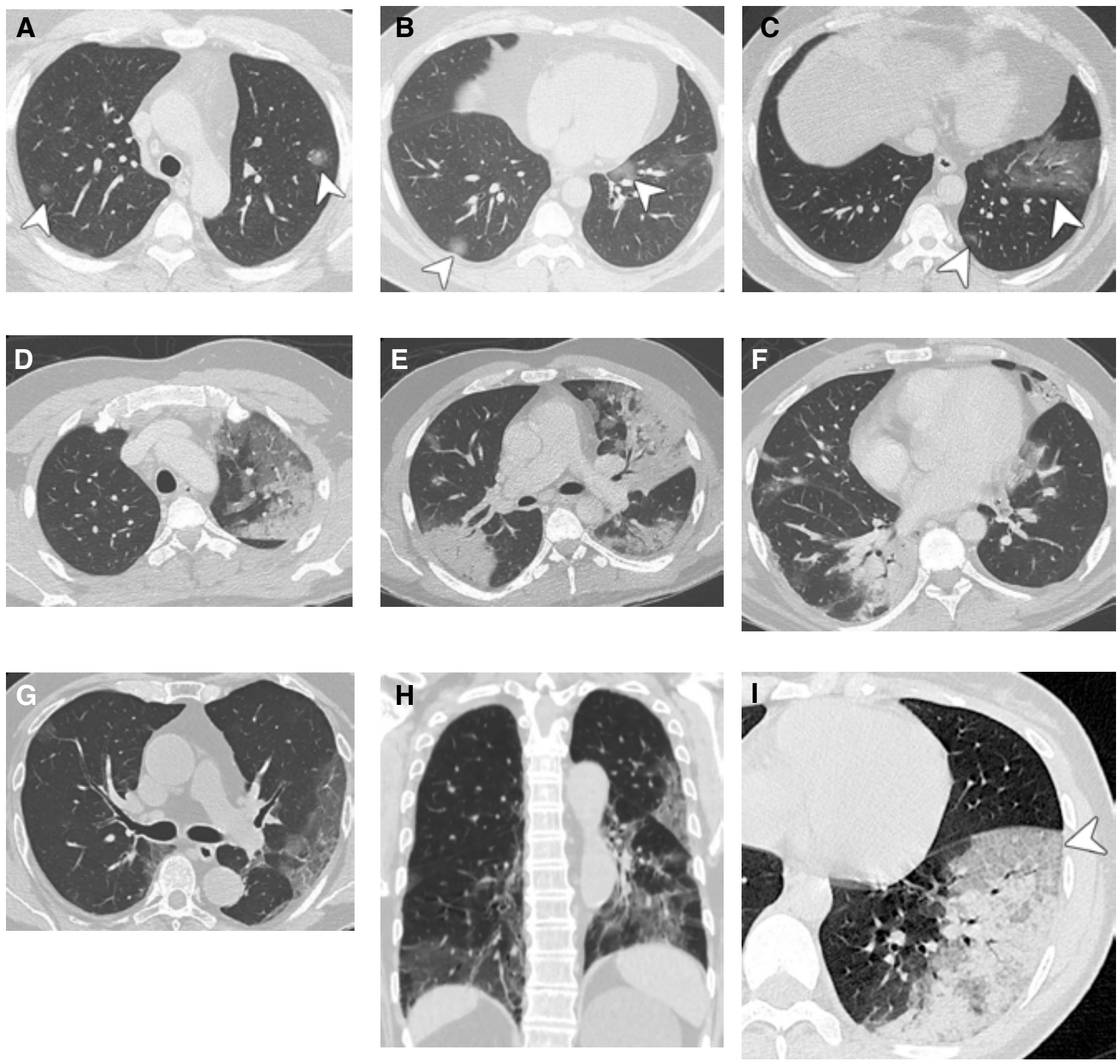

Figura 1: Hallazgos tomográficos frecuentemente reportados en neumopatía por COVID-19, en tres pacientes con enfermedad confirmada mediante PCR. Paciente $1(A-C)$ : Opacidades pulmonares bilaterales con densidad en vidrio esmerilado (puntas de flecha), de morfología redondeada y distribución predominantemente periférica. Paciente 2 ( $D$ F): Opacidades pulmonares mixtas, con significativo componente de condensación, predominio periférico y morfología redondeada. Paciente 3 (G-H): Opacidades con densidad en vidrio esmerilado de distribución predominantemente periférica e inferior. Paciente 4 (I): Opacidad pulmonar mixta en el lóbulo inferior izquierdo, que en su aspecto anterior (punta de flecha) presenta engrosamiento intersticial configurando un patrón de tipo empedrado (crazy paving). 

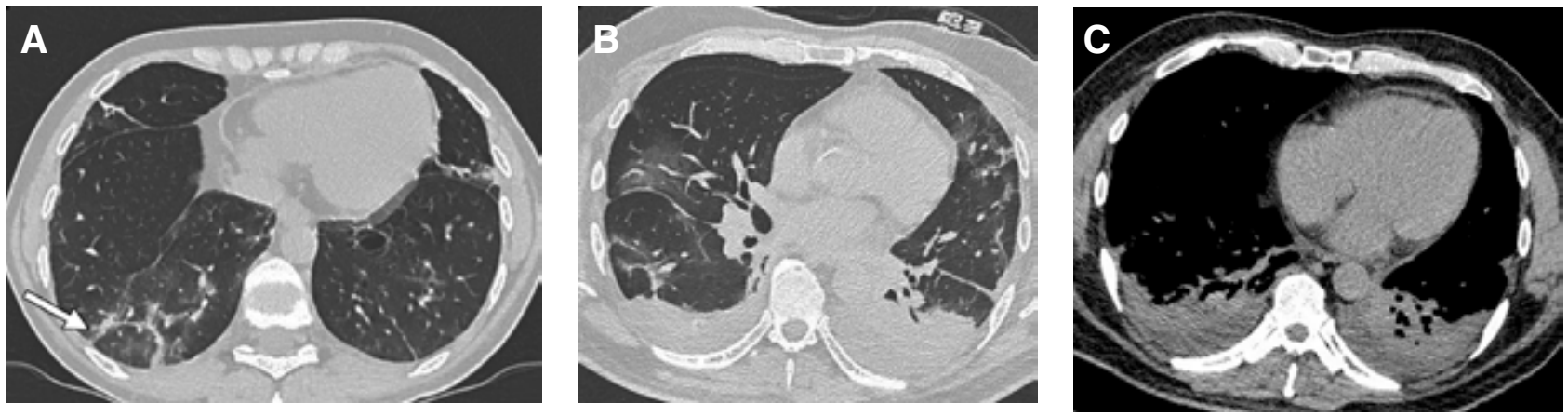

Figura 2: Hallazgos tomográficos infrecuentes en infección por COVID-19. Paciente 1 (A): Opacidad lineal de morfología semiredonda en el lóbulo inferior derecho que rodea un área central con tenue densidad de "vidrio esmerilado", configurando el denominado signo del halo inverso (flecha), descrito aproximadamente en un 10\%. Paciente 2 (B-C): opacidades pulmonares bilaterales con densidad en vidrio esmerilado de distribución periférica en ventana pulmonar, (B) compatibles con hallazgos frecuentes en infección por COVID-19, sin embargo, en ventana mediastínica (C) se observa además un leve derrame pleural, hallazgo infrecuente que se ha reportado en series con una frecuencia de aproximadamente un 4 a $7 \%$ de las TC de pacientes con COVID-19.

Tabla 1. Terminología sugerida para el informe estructurado en COVID-19 en tomografía computada, basada en consenso de la Sociedad Norteamericana de Radiología ${ }^{8}$. Abreviaciones: OVE = opacidades con densidad en vidrio esmerilado.

\begin{tabular}{|c|c|c|}
\hline Patrón & Hallazgos & Impresión sugerida \\
\hline Típico & $\begin{array}{l}\text { OVE de distribución bilateral y periférica: } \\
\text { +/- Focos de condensación } \\
\text { +/- Líneas intralobulillares (patrón crazy-paving) } \\
\text { ó } \\
\text { OVE multifocales con morfología redondeada: } \\
\text { +/- Focos de condensación } \\
\text { +/- Líneas intralobulillares (patrón crazy-paving) }\end{array}$ & $\begin{array}{l}\text { "Hallazgos tomográficos (frecuentemente } \\
\text { reportados) (altamente sugerentes) (clási } \\
\text { cos) de/en neumonía viral COVID-19. El } \\
\text { diagnóstico diferencial corresponde a } \\
\text { neumonía viral por diferente agente } \\
\text { (ej: influenza) y neumonía organizante." }\end{array}$ \\
\hline Indeterminado & $\begin{array}{l}\text { Ausencia de hallazgos típicos y: } \\
\text { Presencia de: } \\
\text { OVE multifocales, difusas, perihiliares o unilaterales } \\
\text { con o sin condensación, sin una distribución } \\
\text { periférica ni morfología redondeada. } \\
\text { ó } \\
\text { Escasas y pequeñas OVE sin una distribución } \\
\text { periférica ni morfología redondeada. }\end{array}$ & $\begin{array}{l}\text { "Hallazgos tomográficos posibles de ob } \\
\text { servar en neumonía viral tipo COVID-19, } \\
\text { sin embargo, inespecíficos y que pueden } \\
\text { ser manifestación de otro proceso infec- } \\
\text { cioso o no infeccioso." }\end{array}$ \\
\hline Atípico & $\begin{array}{l}\text { Ausencia de hallazgos típicos e indeterminados y } \\
\text { Presencia de: } \\
\text { Condensación lobar o segmentaria única, sin OVE. } \\
\text { Nódulos centrolobulillares con morfología de árbol } \\
\text { en brote. } \\
\text { Cavitación pulmonar } \\
\text { Engrosamiento septal interlobulillar liso con } \\
\text { derrame pleural }\end{array}$ & $\begin{array}{l}\text { "Hallazgos tomográficos atípicos o escasa- } \\
\text { mente reportados en neumonía viral tipo } \\
\text { COVID-19. Se sugiere considerar un } \\
\text { diagnóstico alternativo para los hallazgos } \\
\text { imagenológicos." }\end{array}$ \\
\hline Negativo & $\begin{array}{l}\text { Ausencia de hallazgos tomográficos sugerentes } \\
\text { de neumonía. }\end{array}$ & $\begin{array}{l}\text { "Tomografía computada sin hallazgos su } \\
\text { gerentes de neumonía. Nota: Considerar } \\
\text { que en fases precoces de enfermedad } \\
\text { COVID-19 pueden no observarse altera- } \\
\text { ciones tomográficas." }\end{array}$ \\
\hline
\end{tabular}


Impresión sugerida: Hallazgos tomográficos [frecuentemente reportados] [altamente sugerentes] [clásicos] de/en neumonía viral COVID-19. El diagnóstico diferencial corresponde a neumonía viral por diferente agente (ej: influenza) y neumonía organizante.

B) Patrón indeterminado: Hallazgos reportados en neumonías por COVID-19, pero que carecen de especificidad suficiente como para un diagnóstico de certeza de la enfermedad. Ejemplo: OVE de distribución difusa y sin claro predominio zonal hacia inferior ni morfología redondeada, dado que ocurre además en otras etiologías (ej: hemorragia alveolar, neumonía por P. jiirovecii, entre otras) (Figura 3C y D).

Impresión sugerida: Hallazgos tomográficos posibles de observar en neumonía viral tipo $\mathrm{CO}$ VID-19, sin embargo, inespecíficos y que pueden ser manifestación de otro proceso infeccioso o no infeccioso.
C) Patrón atípico: Hallazgos reportados como poco comunes en neumonías por COVID-19, más típicos de otras enfermedades, como neumonía bacteriana, neumonía necrotizante, entre otras. Ejemplos: nódulos centrolobulillares con morfología de árbol en brote, cavitación pulmonar, derrame pleural (Figura 3E y F). Impresión sugerida: Hallazgos tomográficos atípicos o escasamente reportados en neumonía viral tipo COVID-19. Se sugiere considerar un diagnóstico alternativo para los hallazgos imagenológicos.

D) Negativo para neumonía: Estudios sin hallazgos tomográficos sugerentes de infección. Es relevante mencionar que en fases precoces de la enfermedad pueden no observarse alteraciones tomográficas (Ver Evolución temporal) y por lo tanto una TC sin alteraciones no descarta la presencia de infección por COVID-19 (Figura 3G).
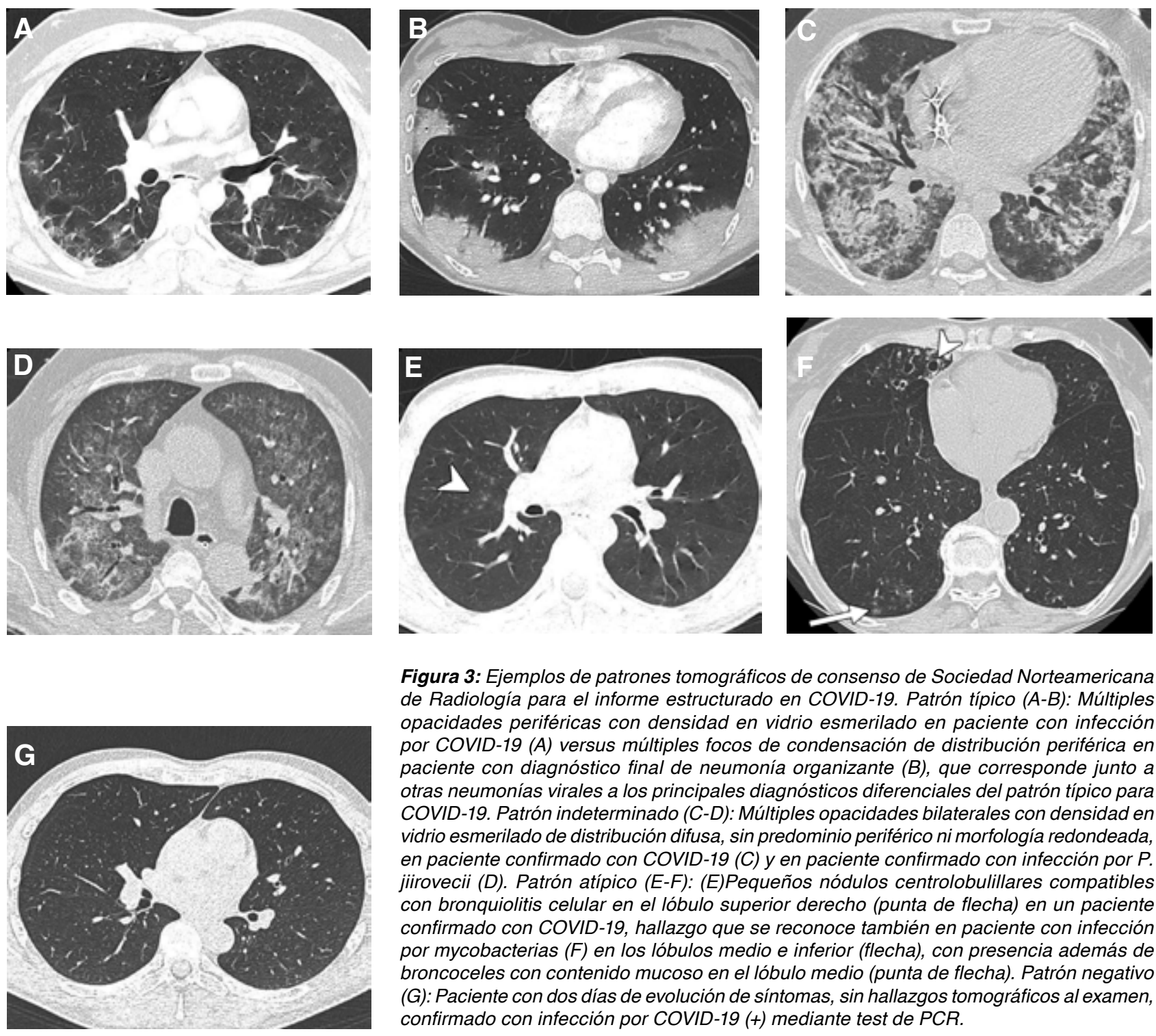

Figura 3: Ejemplos de patrones tomográficos de consenso de Sociedad Norteamericana de Radiología para el informe estructurado en COVID-19. Patrón típico (A-B): Múltiples opacidades periféricas con densidad en vidrio esmerilado en paciente con infección por COVID-19 (A) versus múltiples focos de condensación de distribución periférica en paciente con diagnóstico final de neumonía organizante $(B)$, que corresponde junto a otras neumonías virales a los principales diagnósticos diferenciales del patrón típico para COVID-19. Patrón indeterminado (C-D): Múltiples opacidades bilaterales con densidad en vidrio esmerilado de distribución difusa, sin predominio periférico ni morfología redondeada, en paciente confirmado con COVID-19 (C) y en paciente confirmado con infección por $P$. jiirovecii (D). Patrón atípico (E-F): (E)Pequeños nódulos centrolobulillares compatibles con bronquiolitis celular en el lóbulo superior derecho (punta de flecha) en un paciente confirmado con COVID-19, hallazgo que se reconoce también en paciente con infección por mycobacterias $(F)$ en los lóbulos medio e inferior (flecha), con presencia además de broncoceles con contenido mucoso en el lóbulo medio (punta de flecha). Patrón negativo (G): Paciente con dos días de evolución de síntomas, sin hallazgos tomográficos al examen, confirmado con infección por COVID-19 (+) mediante test de PCR. 
Impresión sugerida: Tomografía computada sin hallazgos sugerentes de neumonía. Nota: Considerar que en fases precoces de enfermedad por COVID-19 pueden no observarse alteraciones tomográficas.

Nos parece relevante advertir el efecto que tiene la probabilidad pretest de COVID-19 en los valores predictivos del consenso. En específico, dada la alta carga existente a la fecha en nuestro país de infección por SARS-CoV-2, y la baja incidencia relativa de otras patologías respiratorias, los patrones tomográficos "indeterminado", "atípico" y "negativo" presentan finalmente un porcentaje no despreciable de confirmación de infección por COVID-19. Lo anterior en parte se demuestra en un estudio reciente ${ }^{10}$ que reportó test de PCR positivo en aproximadamente $50 \%$ de pacientes con patrón tomográfico "indeterminado", $5 \%$ en pacientes con el patrón "atípico" y $20 \%$ con patrón "negativo".

\section{CO-RADS}

El 27 de abril ${ }^{11}$, la Sociedad Neerlandesa de Radiología publicó un nuevo sistema de reportes e información para COVID-19 denominado CO-RADS (Tabla 2), que en base a hallazgos tomográficos establece una probabilidad de infección por COVID-19, desde muy bajo nivel de sospecha (CO-RADS 1) hasta muy alto (CO-RADS 5). Los valores de CO-RADS 0 y 6 corresponden respectivamente a calidad insuficiente de la imagen o imágenes incompletas, y COVID-19 confirmado mediante RT-PCR. Para la construcción de este sistema se utilizaron 105 TC de pacientes analizados por 8 observadores independientes, demostrando un buen rendimiento para predecir la presencia de COVID-19 en pacientes con síntomas moderados a severos. La experiencia en su uso aún es limitada debido a lo reciente de su publicación, pero constituye una alternativa potencial a considerar.

\section{Severidad}

Estudios han buscado correlacionar los hallazgos de TC con evoluciones clínicas desfavorables, así como también establecer un score de severidad y valor pronóstico ${ }^{12}$. Estos han demostrado que pacientes con enfermedad leve presentan un menor número de segmentos pulmonares afectados (mediana de 7.5 segmentos en un estudio), alteraciones que se distribuyen principalmente en la periferia del parénquima y una mayor prevalencia de OVE por sobre focos de condensación. Por otro lado, en casos más severos se ha observado un mayor número de segmentos afectados (mediana 17.5), distribución de las opacidades preferentemente central y periférica (95\%), focos de condensación, y mayor proporción de casos con broncograma aéreo, engrosamiento septal interlobulillar, derrame pleural y adenopatías mediastínicas ${ }^{13}$.

Yang $\mathrm{R}$ et al. desarrollaron un score de severidad (Chest CT severity score $)^{14}$ para diferenciar casos leves de severos basado en la extensión del daño pulmonar por COVID-19. Para esto, dividieron los 18 segmentos pulmonares en 20 regiones, asignando a cada una de estas un puntaje según el área comprometida: 0 puntos si no existían opacidades presentes, 1 punto para un compromiso menor a $50 \%$, y 2 puntos si el compromiso es mayor o igual a 50. La suma total de puntos indica el score de enfermedad. Demostraron así diferencias en score entre enfermedad clínica leve y severa, la primera con una media de 13 puntos; y la segunda, 23.5, estableciendo un puntaje de corte óptimo de 19.5 que alcanza una sensibilidad de $83 \%$ y especificidad de $94 \%$ para diferenciar casos leves de graves, con un alto valor predictivo negativo de $96 \%$.

Tabla 2. Clasificación CO-RADS para tomografía computada ${ }^{(11)}$. Abreviaciones: $R T-P C R=$ reacción en cadena de polimerasa con transcriptasa reversa.

\begin{tabular}{|c|c|c|}
\hline $\begin{array}{l}\text { Categoría } \\
\text { CO-RADS }\end{array}$ & $\begin{array}{l}\text { Nivel de sospecha para daño } \\
\text { pulmonar atribuible a } \\
\text { COVID-19 }\end{array}$ & Resumen \\
\hline $\begin{array}{l}0 \\
1 \\
2 \\
3 \\
4 \\
4 \\
6\end{array}$ & $\begin{array}{l}\text { No interpretable } \\
\text { Muy baja } \\
\text { Baja } \\
\text { Equívoca } \\
\text { Alta } \\
\text { Muy alta } \\
\text { Confirmado }\end{array}$ & $\begin{array}{l}\text { Examen técnicamente insuficiente para asignar un score. } \\
\text { Normal o etiología no infecciosa } \\
\text { Hallazgos típicos para otra infección pero no COVID-19 } \\
\text { Hallazgos compatibles con COVID-19, pero también para otras } \\
\text { enfermedades } \\
\text { Hallazgos sospechosos de COVID-19 } \\
\text { Hallazgos típicos para COVID-19 } \\
\text { RT-PCR (+) para SARS-CoV-2 }\end{array}$ \\
\hline
\end{tabular}




\section{Embolia pulmonar}

La incidencia de enfermedad pulmonar embólica (EP) en pacientes con COVID-19 sometidos a angiografía por tomografía computada (AngioTC) se ha reportado en aproximadamente un $30 \%{ }^{15}$, lo que a su vez se correlaciona con niveles más elevados de dímero-D que pacientes sin EP (mediana 6110 ug/L vs 1920 ug/L). El fenómeno fisiopatológico postulado corresponde al desarrollo de procesos trombo-inflamatorios secundarios a la infección, descritos previamente en MERS ${ }^{16}$. Esta tasa de TEP es mayor que las de pacientes críticos y los pacientes en servicios de urgencia sin COVID-19. También se han reportados otros eventos tromboembólicos como trombosis de la vasculatura renal, infartos cerebrales e isquemia de extremidades ${ }^{17}$.

\section{Radiografía de tórax}

El Colegio Americano de Radiología considera a la radiografía de tórax como un estudio recomendado en sus criterios de pertinencia de indicación de exámenes en pacientes con enfermedad respiratoria aguda ${ }^{18}$. Tiene ventajas comparativas respecto de la TC en el contexto de la pandemia COVID-19 que incluyen su fácil accesibilidad, menor dosis de radiación y posibilidad de realizar examen portátil disminuyendo la probabilidad del contagio del personal de salud.

\section{Hallazgos radiológicos}

Los hallazgos de infección por COVID-19 en RxT descritos a la fecha reflejan los mismos hallazgos descritos para la TC. En un estudio de 64 pacientes con enfermedad confirmada ${ }^{19}$, radiografías iniciales demostraron tanto focos de condensación (59\%) como

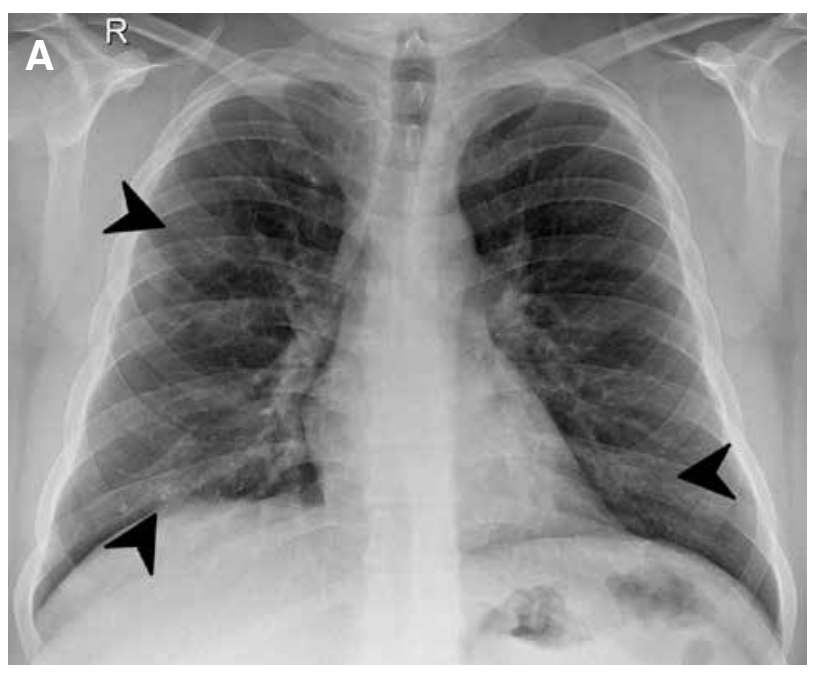

OVE (41\%), que se distribuyeron de forma bilateral $(63 \%)$, basal $(63 \%)$ y periférica $(51 \%)$. Hallazgos infrecuentes correspondieron a derrame pleural (3\%) y nódulos pulmonares (0 casos) (Figura 4).

\section{Informe estructurado}

Sociedad Británica de Imagenología Torácica (BSTI)

El día 16 de marzo, la BSTI propone una clasificación de reporte estructurado para radiografía de tórax en COVID-19 basada en las características, ubicación y predominio zonal de las alteraciones radiológicas ${ }^{20}$ (Tabla 3).

Para su aplicación, se requiere de dividir arbitrariamente ambos volúmenes pulmonares en regiones central y periférica y en mitades superior e inferior. Para la primera división, nuestro grupo utiliza una línea oblicua paralela al borde pleural externo, desde el punto medio del hemidiafragma hacia cefálico, y para la segunda división una línea horizontal desde el margen superior de los hilios pulmonares (Figura 5).

Para definir predominio zonal en este sistema, utilizamos como regla un compromiso pulmonar mayor a $50 \%$ de una ubicación en el caso de una opacidad única, o de más de un $50 \%$ de una ubicación respecto al total de compromiso pulmonar, en el caso de más de una opacidad presente.

Los 4 patrones radiológicos del sistema BSTI corresponden a:

A) Clásico / Probable COVID-19: Múltiples opacidades pulmonares bilaterales, ya sea focos de condensación y/o vidrio esmerilado, con predominio zonal inferior y periférico. Se incluyen también múltiples opacidades bilaterales que presentan predominio zonal periférico, pero equivalente entre mitades superior e inferior (sin predominio inferior) (Figura 6A y B).

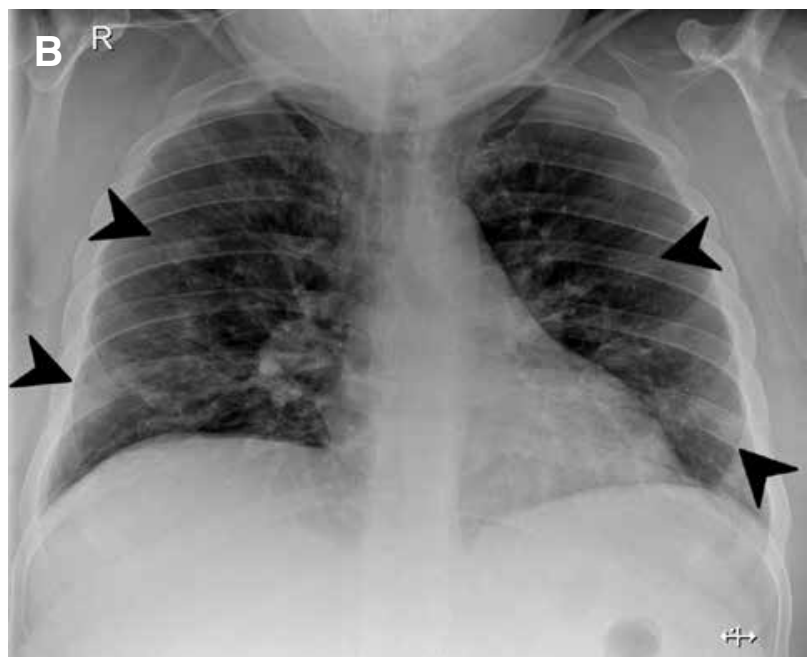

Figura 4: Alteraciones radiológicas frecuentes en pacientes con infección por COVID-19. Las alteraciones en radiografía de tórax son similares las descritas en tomografía computada, siendo las alteraciones más frecuentes la presencia de opacidades con densidad en vidrio esmerilado bilaterales (puntas de flecha) que adoptan una distribución periférica. Pueden también observarse focos de condensación de similar distribución. Hallazgos poco frecuentes corresponden a derrame pleural, nódulos pulmonares y adenopatías. 
Tabla 3. Clasificación BSTI de reporte estructurado para COVID-19 en radiografía de tórax ${ }^{20}$. Abreviaciones: RT-PCR = reacción en cadena de polimerasa con transcriptasa reversa. OVE = opacidades con densidad en vidrio esmerilado.

\begin{tabular}{|l|l|}
\hline Patrón & Hallazgos \\
\hline Clásico / Probable de COVID-19 & $\begin{array}{l}\text { Focos de condensación y/u OVE múltiples, bilaterales, de predominio } \\
\text { perifé rico e inferior. }\end{array}$ \\
& $\begin{array}{l}\text { Focos de condensación y/u OVE múltiples, bilaterales, de predominio } \\
\text { perifé rico, sin predominio inferior ni superior. }\end{array}$ \\
Indeterminado para COVID-19 & $\begin{array}{l}\text { Alteraciones que no cumplen con criterios de un patrón clásico ni un patrón } \\
\text { No-COVID-19 }\end{array}$ \\
& $\begin{array}{l}\text { Alteraciones sugerentes de otra patología con mayor probabilidad a COVID-19: } \\
\text { Neumonía única lobar o segmentaria } \\
\text { Derrame pleural } \\
\text { Edema intersticial } \\
\text { Neumotórax } \\
\text { Otros: masas, atelectasia lobar, fibrosis pulmonar. }\end{array}$ \\
\hline
\end{tabular}

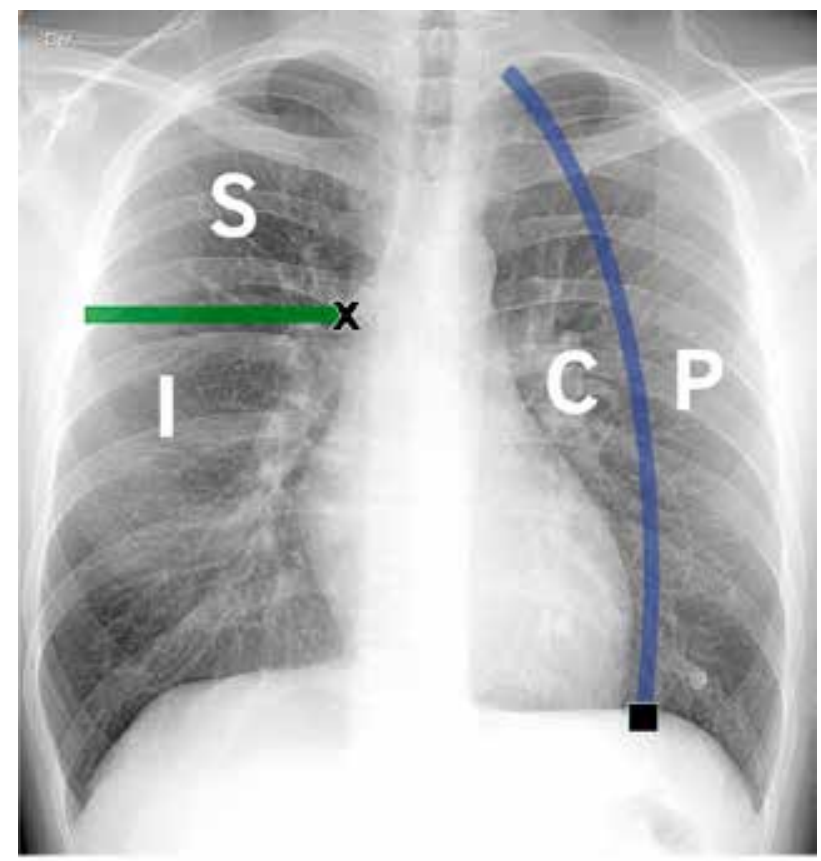

\section{$\mathbf{X}$ : Margen superior del hilio pulmonar 口 : Punto medio del hemidiafragma S: Superior - I: Inferior C: Central - P: Periférico}

Figura 5: Líneas de división utilizadas por nuestro grupo para el sistema de clasificación BSTI. Para dividir las mitades superior (S) e inferior (I) se traza una línea horizontal desde el margen superior de los hilios pulmonares, y para dividir las regiones centrales $(C)$ y periférica $(P)$ una línea oblicua, paralela al borde pleural externo, trazada desde el punto medio del hemidiafragma hacia cefálico.
B) Indeterminado para COVID-19: Alteraciones presentes, pero que no cumplen con los criterios de un patrón clásico ni tampoco de un patrón No-COVID-19. Ejemplos: Opacidades múltiples de distribución difusa, sin predominio zonal; Focos de condensación múltiples, periféricos y de predominio superior; Focos de condensación múltiples unilaterales y de predominio periférico (Figura 6C).

C) No-COVID-19: Alteraciones presentes, pero sugerentes de otra patología. Ejemplos: Foco de condensación único, patrón reticular intersticial (edema intersticial, linfangitis carcinomatosa), patrón reticular de tipo bronquiolitis, fibrosis pulmonar, enfisema pulmonar, nódulos / masas pulmonares, atelectasia lobar, neumotórax, derrame pleural, cardiomegalia (Figuras 6D y E).

D) Normal: Examen sin hallazgos radiológicos o bien no correlacionados con síntomas clínicos (ejemplo: cicatrices pulmonares, granulomas calcificados, atelectasias lineales). Al igual que en TC, una radiografía de tórax sin hallazgos patológicos no descarta la posibilidad de infección por COVID-19, por lo que sugerimos concluir con el siguiente enunciado: Examen sin hallazgos radiológicos de neumonía. Indispensable correlación con test de PCR (Figura 6F).

\section{Valor pronóstico}

Recientemente, Toussie et. al investigaron la radiografía de tórax como un método para predecir outcomes clínicos ${ }^{21}$ en pacientes con infección por COVID-19. Para ello, utilizaron datos de pacientes 
entre 21 y 50 años, dividiendo cada pulmón en 3 zonas (superior, media e inferior) y asignando un puntaje total de acuerdo a la presencia (1) o ausencia (0) de opacidades. Con un puntaje de corte de 20 más, logró una sensibilidad (S) y especificidad (E) de $66 \%$ y $79 \%$ respectivamente para predecir hospitalización, mientras que, para aquellos pacientes hospitalizados, el compromiso de 3 o más zonas logró una $S$ y $E$ de $68 \%$ y $67 \%$ respectivamente para predecir intubación. Para otros outcomes, como son estadía prolongada y sepsis, no se logró identificar una cifra estadísticamente significativa. Esto podría situar a la RxT como un indicador independiente de pronóstico en pacientes con COVID-19.

\section{Ultrasonografía}

El rol de la ultrasonografía en pacientes con COVID-19 está en desarrollo. Entre los hallazgos descritos en series, se encuentran anormalidades en líneas pleurales (100\%), líneas-B (100\%) y consolidación $(64 \%)^{22}$. El derrame pleural se observa con menor frecuencia. Estos hallazgos son más bien inespecíficos y pueden estar en el contexto de distrés respiratorio no COVID, por lo que su utilidad sería más bien como una herramienta complementaria, sobre todo en un escenario clínico con poca disponibilidad de otros recursos de imágenes. Se suma además la necesidad de realizar un correcto aseo del equipo para evitar la diseminación de la infección.

\section{Experiencia local en el Servicio y Departamento de Radiología de la Red de Salud UC-Christus}

Desde la declaración de la fase 4 de la pandemia en Chile (16 de marzo) ${ }^{23}$ nuestro Servicio / Departamento fue tomando medidas orientadas a disminuir el riesgo de contagio por parte de los profesionales, técnicos y administrativos que laboran en sus dependencias (Tabla 4). Estas medidas van en la misma línea de las adoptadas por otros centros radiológicos universitarios de Estados Unidos (Universidad de Washington, Universidad de New York, Universidad
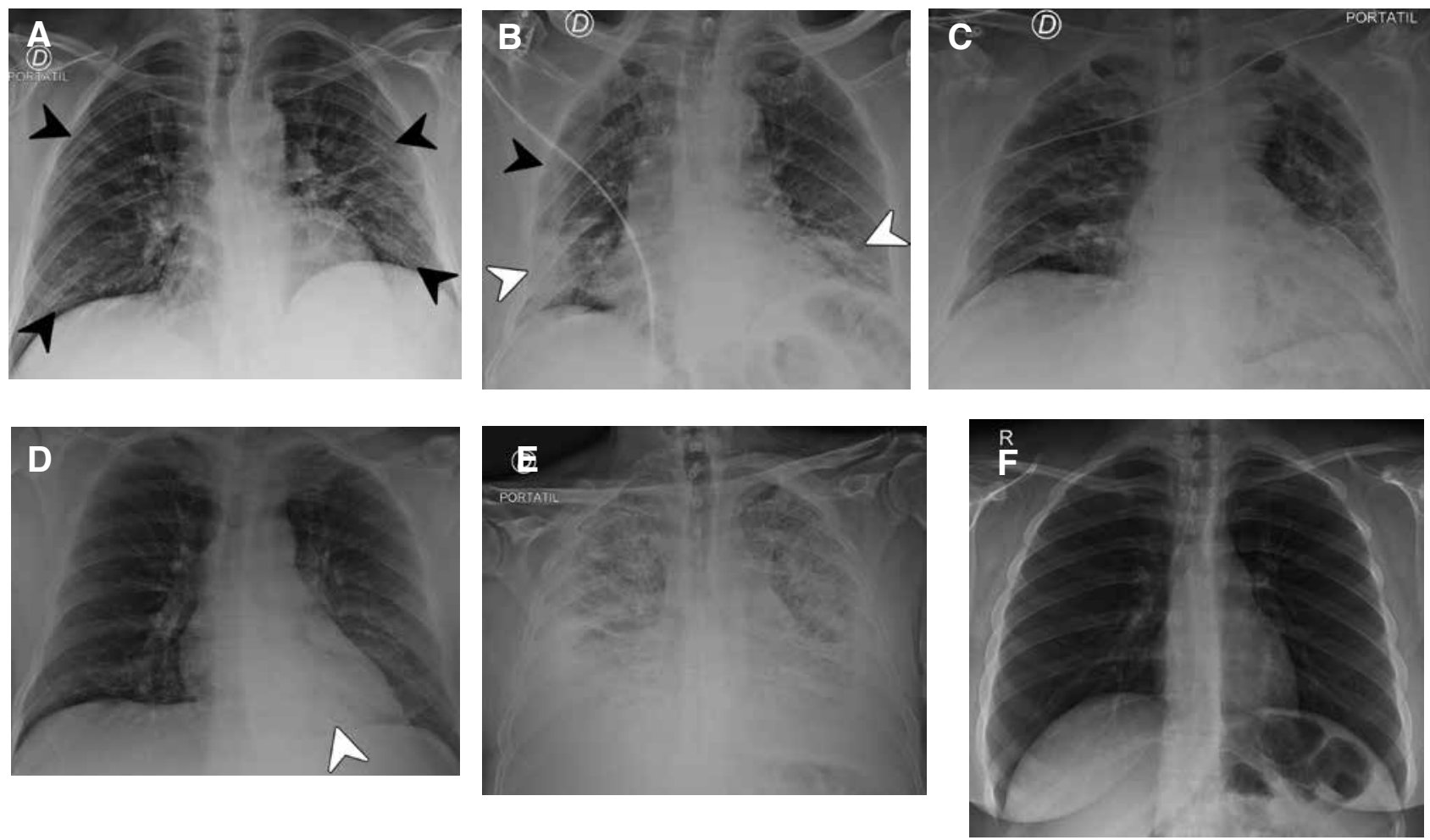

Figura 6: Ejemplos de radiografías de tórax para cada patrón del sistema de reporte estructurado BSTI en COVID-19. Patrón clásico / probable (A-B): Paciente 1 (A) Opacidades con densidad en vidrio esmerilado bilaterales de distribución periférica e inferior (puntas de flecha negra). Paciente 2 (B): Opacidades bilaterales en vidrio esmerilado (puntas de flecha negra) asociadas a focos de condensación múltiples en la distribución descrita (puntas de flecha blanca) Patrón indeterminado $(C)$ : Opacidades con densidad en vidrio esmerilado de distribución difusa, sin predominio zonal inferior ni periférico. Patrón No-COVID-19 (D-E): Paciente (D) con foco de condensación retrocardíaco, unifocal, consistente con neumonía bacteriana. Paciente (E) con signos de edema intersticial y alveolar bilateral, difuso, asociado a derrame pleural bilateral, consistente con insuficiencia cardíaca descompensada. Patrón normal (F): Examen sin hallazgos radiológicos sugerentes de neumonía en paciente con COVID-19 confirmado mediante test de PCR. Es relevante mencionar que este patrón no descarta la presencia de enfermedad. 
Tabla 4. Medidas adoptadas por el Servicio y Departamento de Radiología de la Red de Salud UC-Christus durante el período de pandemia por COVID-19.

\begin{tabular}{|c|c|}
\hline Ámbito & Medidas \\
\hline $\begin{array}{l}\text { Distanciamiento } \\
\text { social }\end{array}$ & $\begin{array}{l}\text { Número restringido de staff / residentes por sala de informe. } \\
\text { Uso individual y no compartido de estaciones de informe, con limpieza frecuente pre } \\
\text { vio y posterior a su uso. } \\
\text { Reducción del número de personas en áreas de informe, restringiendo solo a per- } \\
\text { sonal esencial, staff / residentes: suspensión de rotaciones de internos y residentes } \\
\text { visitantes; interconsultas radiológicas y de TM solo telefónicas; carga en PACS de } \\
\text { exámenes previos solo vía correo electrónico. } \\
\text { Rotaciones "on / off" de staff y residentes. } \\
\text { Apoyo para implementar estaciones de trabajo en el hogar. } \\
\text { Entregas de turno, clases y seminarios del programa de residencia transformadas } \\
\text { a formato virtual: uso de plataformas Canvas y Zoom. } \\
\text { Reuniones clínicas inter-departamentales en formato virtual. }\end{array}$ \\
\hline $\begin{array}{l}\text { Manejo de contactos / } \\
\text { interacciones de alto riesgo }\end{array}$ & $\begin{array}{l}\text { Manejo local de stock de elementos de protección personal (EPP). } \\
\text { Acceso a curso online de EPP. } \\
\text { Pacientes trasladados al servicio de radiología con uso de mascarilla. } \\
\text { Atención de pacientes con EPP por staff/residentes. } \\
\text { Protocolos de limpieza de equipos ecográficos después de cada uso. } \\
\text { Al reanudarse la atención ambulatoria: triage previo por personal de apoyo identifi- } \\
\text { cando síntomas respiratorios o infecciosos. } \\
\text { Diagnóstico de posible COVID-19 en imágenes: notificación como alerta diagnóstica. } \\
\text { Alerta retrospectiva: revisión en PACS del listado de exámenes de un paciente al } \\
\text { momento de ser diagnosticado como COVID-19 en radiografía o TC de tórax, con } \\
\text { el objetivo de identificar estudios por imagen realizados en las } 2 \text { semanas previas } \\
\text { al diagnóstico que puedan haber significado contacto de staff/residentes (ej: eco- } \\
\text { grafía, biopsia por imágenes, etc.) y así realizar notificación correspondiente a los } \\
\text { involucrados } \\
\text { Sistema de notificación inmediata de síntomas respiratorios por parte de staff/resi- } \\
\text { dentes para toma de RT-PCR, identificación de contactos y aislamiento preventivo. }\end{array}$ \\
\hline $\begin{array}{l}\text { Desarrollo y revisión de } \\
\text { información relacionada a } \\
\text { COVID-19 para su } \\
\text { difusión en la } \\
\text { comunidad médica }\end{array}$ & $\begin{array}{l}\text { Guías de uso apropiado de imágenes para COVID-19 en servicio de urgencia. } \\
\text { Jornadas integradas de capacitación en COVID-19 de la Red de Salud UC-Christus } \\
\text { (difundidas por YouTube). } \\
\text { Sesiones docentes semanales intra-departamentales de actualización COVID-19. } \\
\text { Creación de grupo de Investigación en COVID-19 para enfocar misión docente y de } \\
\text { investigación de nuestra institución. Líneas de trabajo: } \\
\text { - Radiografía de tórax e informe estructurado para COVID-19. } \\
\text { - Variabilidad inter-observador en RxT para diagnóstico de COVID-19. } \\
\text { - Signos de respuesta al tratamiento con plasma convaleciente en TC. } \\
\text { - Desarrollo de algoritmos de Inteligencia Artificial en imágenes médicas asocia } \\
\text { das a COVID-19. }\end{array}$ \\
\hline
\end{tabular}

de Wisconsin, etc) ${ }^{24}$, con los objetivos de mantener una operación continua durante la emergencia, apoyar el cuidado de pacientes y mantener un apoyo radiológico diagnóstico e intervencional.

\section{Conclusión}

La actual pandemia por SARS-CoV-2 ha llevado a reorganizar la forma en que los servicios y departamentos académicos de radiología realizan su labor, no solo aportando en el diagnóstico y manejo de estos casos, sino también promoviendo un ambiente seguro para los otros pacientes y el grupo de trabajo radiológico, reestructurando además la forma de hacer docencia y las líneas de investigación al nuevo escenario. Un ejemplo global de estos cambios son los consensos 
que han propuesto las principales sociedades radiológicas para definir correctas indicaciones de imágenes en diferentes escenarios clínicos de la pandemia y la estandarización de la estructura de informes de TC y RxT para pacientes con sospecha de COVID-19.

\section{Agradecimientos}

Los autores agradecen la colaboración del Dr. Rodrigo San Martín Bachmann en la organización del documento.

\section{Referencias}

1. WHO. Director-General's opening remarks at the media briefing on COVID-19. 11 March. (Fecha de citación 14 de junio 2020). Disponible en: https://www.who.int/dg/speeches/detail/who-director-general-s-opening-remarksat-the-media-briefing-on-covid-19---11-march-2020.

2. ACR Recommendations for the use of Chest Radiography and Computed Tomography (CT) for Suspected COVID-19 Infection. (Fecha de citación: 14 de junio 2020). Disponible en: https://www.acr.org/ Advocacy-and-Economics/ACR-Position-Statements/ Recommendations-for-Chest-Radiography-and-CT-forSuspected-COVID19-Infection.

3. Rubin GD, Ryerson CJ, Haramati LB, Sverzellati N, Kanne JP, Raoof S, et al. The Role of Chest Imaging in Patient Management during the COVID-19 Pandemic: A Multinational Consensus Statement from the Fleischner Society. Radiology. 2020 Apr 7; 296(1): 172-180. Disponible en: https://doi.org/10.1148/radiol.2020201365

4. Kim H, Hong H, Yoon SH. Diagnostic Performance of CT and Reverse Transcriptase-Polymerase Chain Reaction for Coronavirus Disease 2019: A Meta-Analysis. Radiology. 2020 Apr 17;201343. Disponible en: https:// doi.org/10.1148/radiol.2020201343

5. Wen Z, Chi Y, Zhang L, Liu H, Du K, Li Z, et al. Coronavirus Disease 2019: Initial Detection on Chest CT in a Retrospective Multicenter Study of 103 Chinese Subjects. Radiol Cardiothorac Imaging. 2020 Apr 1; 2(2): e200092. Disponible en: https://doi.org/10.1148/ ryct.2020200092

6. Caruso D, Zerunian M, Polici M, Pucciarelli F, Polidori T, Rucci C, et al. Chest CT Features of COVID-19 in Rome, Italy. Radiology. 2020 Apr 3; 201237. Disponible en: https://doi.org/10.1148/radiol.2020201237

7. Wang Y, Dong C, Hu Y, Li C, Ren Q, Zhang X, et al. Temporal Changes of CT Findings in 90 Patients with COVID-19 Pneumonia: A Longitudinal Study. Radiology. 2020 Mar 19; 200843. Disponible en: https://doi. org/10.1148/radiol.2020200843

8. Simpson S, Kay FU, Abbara S, Bhalla S, Chung JH, Chung M, et al. Radiological Society of North America Expert Consensus Statement on Reporting Chest CT Findings Related to COVID-19. Endorsed by the Society of Thoracic Radiology, the American College of Radiology, and RSNA. Radiol Cardiothorac Imaging. 2020 Mar 25; 2(2): e200152. Disponible en: https://doi. org/10.1148/ryct.2020200152

9. Sochradi. Capítulo de Tórax toma como modelo propuesta elaborada por la RSNA, SRT y la ACR en informes Covid19, para sugerir formato de informe. (Fecha de citación 14 de junio 2020). Disponible en: https://www.sochradi.cl/2020/05/noticias/capitulo-detorax-toma-como-modelo-propuesta-elaborada-porla-rsna-str-y-la-acr-en-informes-covid19-para-sugerirformato-de-informe.

10. De Jaegere $\mathrm{TMH}$, Krdzalic J, Fasen BACM, Kwee RM. Radiological Society of North America Chest CT Classification System for Reporting COVID-19 Pneumonia: Interobserver Variability and Correlation with RT-PCR. Radiol Cardiothorac Imaging. 2020 Jun 1; 2(3): e200213. Disponible en: https://doi.org/10.1148/ ryct.2020200213

11. Prokop $M$, van Everdingen $W$, van Rees Vellinga $T$, Quarles van Ufford J, Stöger L, Beenen L, et al. CORADS-A categorical CT assessment scheme for patients with suspected COVID-19: definition and evaluation. Radiology. 2020 Apr 27; 201473. Disponible en: https:// doi.org/10.1148/radiol.2020201473

12. Tabatabaei SMH, Talari H, Moghaddas F, Rajebi H. Computed Tomographic Features and Short-term Prognosis of Coronavirus Disease 2019 (COVID-19) Pneumonia: A Single-Center Study from Kashan, Iran. Radiol Cardiothorac Imaging. 2020 Apr 1; 2(2): e200130. Disponible en: https://doi.org/10.1148/ryct.2020200130

13. Yu M, Xu D, Lan L, Tu M, Liao R, Cai S, et al. Thinsection Chest CT Imaging of Coronavirus Disease 2019 Pneumonia: Comparison Between Patients with Mild and Severe Disease. Radiol Cardiothorac Imaging. 2020 Apr 1; 2(2): e200126. Disponible en: https://doi. org/10.1148/ryct.2020200126

14. Yang R, Li X, Liu H, Zhen Y, Zhang X, Xiong Q, et al. Chest CT Severity Score: An Imaging Tool for Assessing Severe COVID-19. Radiol Cardiothorac Imaging. 2020 Mar 30; 2(2): e200047. Disponible en: https://doi. org/10.1148/ryct.2020200047

15. Leonard-Lorant I, Delabranche X, Severac F, Helms J, Pauzet C, Collange O, et al. Acute Pulmonary Embolism in COVID-19 Patients on CT Angiography and Relationship to D-Dimer Levels. Radiology. $2020 \mathrm{Apr}$ 23; 201561. Disponible en: https://doi.org/10.1148/ radiol.2020201561

16. Oudkerk M, Büller HR, Kuijpers D, van Es N, Oudkerk SF, McLoud TC, et al. Diagnosis, Prevention, and Treatment of Thromboembolic Complications in COVID-19: Report of the National Institute for Public Health of the Netherlands. Radiology. 2020 Apr 23; 201629. Disponible en: https://doi.org/10.1148/radiol.2020201629

17. Lushina N, Kuo JS, Shaikh HA. Pulmonary, Cerebral, and Renal Thromboembolic Disease Associated with COVID-19 Infection. Radiology. 2020 Apr 23; 201623. Disponible en: https://doi.org/10.1148/radiol.2020201623

18. Kirsch J, Ramirez J, Mohammed T-LH, Amorosa JK, Brown K, Dyer DS, et al. ACR Appropriateness Criteria Acute Respiratory Illness in Immunocompetent Patients. J Thorac Imaging. 2011; 26(2): W42-W44.

19. Wong HYF, Lam HYS, Fong AH-T, Leung ST, Chin TWY, Lo CSY, et al. Frequency and Distribution of Chest Radiographic Findings in COVID-19 Positive Patients. Radiology. 2020 Mar 27; 201160. Disponible en: https:// doi.org/10.1148/radiol.2020201160

20. BSTI. COVID-19 Reporting templates (Fecha de citación 14 de junio 2020). Disponible en: https://www.bsti. 
org.uk/covid-19-resources/covid-19-bsti-reportingtemplates.

21. Toussie D, Voutsinas N, Finkelstein M, Cedillo MA, Manna S, Maron SZ, et al. Clinical and Chest Radiography Features Determine Patient Outcomes In Young and Middle Age Adults with COVID-19. Radiology. 2020 May 14; 201754. Disponible en: https://doi.org/10.1148/radiol.2020201754

22. Xing C, Li Q, Du H, Kang W, Lian J, Yuan L. Lung ultrasound findings in patients with COVID-19 pneumonia. Crit Care. 2020; 24(1): 174. Disponible en: https://doi.org/10.1186/s13054-020-02876-9

23. Minsal. Coronavirus en Chile pasa a fase 4 y presidente anuncia cierre de fronteras. (Fecha de citación 14 de junio 2020). Disponible en: https:// www.minsal.cl/coronavirus-en-chile-pasa-a-fase4-y-presidente-anuncia-cierre-de-fronteras.

24. Mossa-Basha M, Meltzer CC, Kim DC, Tuite MJ, Kolli KP, Tan BS. Radiology Department Preparedness for COVID-19: Radiology Scientific Expert Panel. Radiology. 2020 Mar 16; 200988. Disponible en: https://doi.org/10.1148/radiol.2020200988 